\title{
Construcții (pseudo)scindate în româna veche
}

\author{
Mihaela Gheorghe* \\ Facultatea de Litere, Universitatea Transilvania din Brașov, Bd. Eroilor 29, 500036 Brașov, România \\ Institutul de Lingvistică „Iorgu Iordan - Al. Rosetti”, Calea 13 Septembrie 13, 050711 București, România
}

\section{Despre articol}

Istoric:

Primit 9 mai 2017

Acceptat 13 mai 2017

Publicat 30 septembrie 2017

Cuvinte-cheie:

construcții scindate

construcții pseudo-scindate

construcții relative

română veche

\begin{abstract}
Rezumat
Articolul examinează trăsăturile sintactice și semantice ale structurilor scindate în limba română veche, în comparație cu tiparele din româna modernă. Prin mecanismul de scindare, în limba actuală se pot obține exclusiv construcții pseudoscindate (structuri de identificare cu relative libere introduse prin ce sau structuri relative cu antecedent, în care constituentul focalizat este plasat la finalul construcției, după copulă, sau tipare inverse, cu constituentul focalizat plasat înaintea copulei și a relativei). Analiza unui corpus de limbă română veche a arătat că aceste construcții erau destul de frecvente, însă tiparele erau mai variate: pe lîngă structurile scindate și pseudo-scindate prototipice, se regăsesc și structuri hibride, care amalgamează trăsături ale celor două variante.
\end{abstract}

\section{Introducere}

Pornind de la Jespersen (1937/1984), descrierea construcțiilor scindate acoperă o bogată bibliografie. Mai numeroase sînt studiile care acordă atenție sintaxei structurilor scindate (Akmajian, 1970; Gundel, 1977; Higgins, 1979; Boškovic, 1997; Iatridou \& Varlokosta, 1998; Reeve, 2011, 2012; Hartmann \& Tonjes, 2013; Hedberg, 2013), fără a se neglija însă descrierea trăsăturilor lor semantice și pragmatice (v. Prince, 1981; Declerck, 1984, 1988; Halliday, 1985; Lambrecht, 2001).

Pentru subiectul articolului de față ne interesează distincția cu care operează teoria sintactică curentă între construcții scindate și construcții pseudo-scindate.

Schema generală a unei construcții scindate prototipice (1) este [expletiv + copulă + XP FOCALIZAT + relativă restrictivă] (Reeve, 2012, p. 1), unde XP focalizat poate fi subiect (1a) sau obiect (1b).
a. It
was JoHn who
left
[expletiv] a fost $E L$
care/cine
a plecat
'Ion a fost cel care a plecat'
b. It
was A RED BAG
[expletiv] a fost
O ROȘIE GEANTĂ
that I bought
'Ceea ce am cumpărat a fost o geantă roșie'

Schema generală a unei construcții pseudo-scindate (2) este [relativă + copulă + XP FOCALIZAT], aceasta putînd fi organizată în varianta de bază (2a) sau în varianta inversată [XP FOCALIZAT + copulă + relativă] (2b) (v. Huddlestone et al., 2002, p. 1414). În sens restrîns, construcții pseudo-scindate sînt considerate relativele libere incluse în tipare de identificare în care ocupă poziție tematică, precum cele de sub (2a,b) (v. Prince, 1978, p. 883); într-o accepție mai generală, însă, se includ în această clasă și construcții relative cu antecedent nominal de tip neutru (lucrul/faptul/modul/locul/motivul etc.) (2c) ori care au ca antecedent un cuantificator universal $(2 \mathrm{~d})$ (Collins, 1991, p. 27) și a căror schemă generală este [XP FOCALIZAT + copulă + antecedent + relativa $]$.

\footnotetext{
*Adresă de corespondență: m.gheorghe@unitbv.ro.
} 


(2) a. What I bought was a red bag
Ce am cumpărat a fost o geantă roșie
'Ceea ce am cumpărat a fost o geantă roșie'
b. A red bag was what I bought
Ogeantă roșie a fost ce am cumpărat
'O geantă roșie a fost ceea ce am cumpărat'
c. The place where John saw Mary was in front of the bank
Locul unde John a văzut Mary a fost in fața băncii
'În fața băncii e locul unde a văzut-o John pe Mary'
d. All he wanted was a hamburger
Tot el a dorit a fost un hamburger
'Tot ce (și-)a dorit a fost un hamburger'

Lucrarea de faţă își propune o inventariere a tiparelor de construcții scindate în limba română veche și confruntarea structurilor identificate cu tiparele din româna contemporană.

Descrierile din bibliografia românească a problemei (v. Șerbănescu, 1996; Pană Dindelegan, 2013, p. 488) arată că în limba actuală strategia scindării conduce exclusiv la construcții pseudo-scindate; acestea sînt fie structuri de identificare cu relative libere introduse prin ce (3a) (după tiparul [relativă + copulă + XP FOCALIZAT]), fie structuri relative cu un antecedent din categoriile menţionate de Collins (1991; v. supra): un nominal cu valoare generalizatoare $(3 \mathrm{~b}, \mathrm{c})$ sau cuantificatorul universal tot $(3 \mathrm{~d})$, cu tiparul $[$ antecedent + relativă + copulă + XP FOCALIZAT $]$.

Sînt posibile și construcții pseudo-scindate inverse, avînd schema [XP FOCALIZAT + copulă + antecedent + relativă], cu constituent focalizat extras din diferite poziții [subiect în (4a), sau obiect direct / obiect prepozițional / adjunct în $(4 \mathrm{~b})]^{1}$.

(3) a. [Ce mă supără cel mai tare] este CĂ NU AI RĂBDARE.

b. Ceea [ce mă supără cel mai tare] este CĂ NU AI RĂBDARE.

c. Chestia [care mă supără cel mai tare] este CĂ NU AI RĂBDARE.

d. Tot [ce mă supără] este CĂ NU AI RĂBDARE.

(4) a. CĂ NU AI RĂBDARE este ceea [ce mă supără cel mai tare].

b. EL este cel [pe care l-ai întîlnit ieri] / [despre care am vorbit] / [la care ne ducem].

\section{Tipare de construcții scindate în limba română veche}

Investigarea unui corpus de texte românești din secolele al XVI-lea - al XVIII-lea a pus în evidență existența a numeroase structuri în care focalizarea unui constituent se produce printr-un mecanism de scindare. Am remarcat că, pe de o parte, construcțiile identificate se deosebesc de cele din româna actuală printr-o serie de trăsături morfosintactice și de organizare generală (pe care le vom detalia în cele ce urmează), pe de altă parte, am remarcat absența tiparelor pseudo-scindate ilustrate sub (3a-d) și a tiparului invers de sub (4a).

\footnotetext{
${ }^{1}$ Deși nu este susținută, deocamdată, de rezultatele unei investigații cantitative, se impune, totuși, observația că în româna modernă varianta de pseudo-scindare [XP FOCALIZAT + copulă + relativă $]$ este aproape absentă (sau, mai exact, este limitată la situațiile în care constituentul focalizat este obiect, iar relativa este introdusă prin $c e$ ), fiind preferată construcția cu antecedent $[X P$ FOCALIZAT + copulă + antecedent + relativă $]$. O distribuție limitată pare a avea și structura $[$ relativă + copulă $+X P$ FOCALIZAT], comparativ cu tiparele de sub $(3 \mathrm{~b}-\mathrm{d})$, în care relativa are ca antecedent un nominal cu sens generalizator. S,i în acest tipar, conectorul relativei este mai ales ce, iar constituentul focalizat este obiect. Ambele tipuri de construcții sînt în variație liberă cu cele în care relativa introdusă prin ce are drept antecedent pronumele semiindependent ceea. Această remarcă poate conduce la concluzia că, în fapt, relativa fără antecedent este o variantă a construcției cu antecedentul ceea. Pentru mai multe date în legătură cu distribuția grupării (ceea) ce în relativele din româna actuală, v. Gheorghe (2004, p. 140-148).
} 


\subsection{Construcții scindate}

Corpusul a relevat existența unor structuri scindate asemănătoare cu cele prototipice (în legătură cu care sa afirmat că româna prezintă o idiosincrasie), organizate după tiparul [copulă + XP FOCALIZAT + relativă]. Structurile de sub (5) sînt similare cu cele de sub (1), cu deosebirea că nu prezintă un pronume expletiv². Este de remarcat varietatea lor, atît sub aspectul poziției sintactice din care este extras constituentul focalizat [subiect în $(5 \mathrm{a}, \mathrm{d}, \mathrm{e})$, adjunct în $\left(5 \mathrm{~b}_{1}\right)$ și obiect prepoziţional în $\left(5 \mathrm{~b}_{2}, \mathrm{c}\right)$ ], cît și sub aspectul conectorului relativei. În plus, se observă că XP focalizat poate avea structură simplă [nume propriu sau demonstrativ $(5 \mathrm{a}, \mathrm{b})]$ sau complexă $(5 \mathrm{c}, \mathrm{d}, \mathrm{e})$. Constituentul complex focalizat cuprinde un antecedent pronominal și o relativă restrictivă (purtătoare a informației focale). Relativa poate avea și un antecedent pronominal ( $5 f$ ).

(5) a. Și iaste ȚARINA LUI EFRON [carea era în peștira cea îndoită] $($ BB.1688, 15)

b. Au nu iaste ACESTA [den carele bea domnu-nostru] și [cu carele vrăjaște]? (Po.1582, 155)

c. și-i tremease cătră Domnul Isus Hristos, să întreabe pre el de iaste ACESTA [CE-AU VENIT] [de carele zice scriptura și glasurile prorocești]... $\left(\mathrm{CC}^{2} .1581,586\right)$

d. De nu acesta, au iaste Cela [CE Răsipia întru Ierusalim] [cine meniia numele acesta ....]? (Св.1559-60, 98)

e. era OARECINE [DE-L CHEMA SAMPSON] [ce era mai cu virtute de toț cîți era pe lume] (FD.1592-604, 568 ${ }^{\mathrm{r}}$ )

f. şi atunce iaste CUVîNTUL acela [ce zice] (AD.1722-5, 92, 83 $\left.{ }^{\mathrm{r}}\right)$

\subsection{Construcțiipseudo-scindate prototipice}

Bine reprezentată în corpus este schema de construcție pseudo-scindată prototipică: [XP FOCALIZAT + copulă + relativă ], în legătură cu care observam în nota 1 că în româna modernă este aproape absentă (reducîndu-se, în puținele ocurențe, la o unică ipostază—cu conectorul ce și cu element focalizat extras din poziție de obiect).

Exemplele de sub (6) arată că în româna veche tiparele sînt mai variate. Pe de o parte, constituentul focalizat poate fi subiect, pe de altă parte, subordonata relativă poate avea și alți conectori în afară de $c e$ [v. $(6 a, c, d)]:$

(6) a. Că TU ești [cinre me-au trasu de zgău] (...) (PH.1500-1510, 103, 17²)

b. Știa-l el că ACESTA era [ce derept milosteniia ședea pre lîngă înfrunsețatele uși ale besearecilor] (CP.1570, 29)

c. Că (...) ACEla iaste [de-l măreaște Domnul] $\left(\mathrm{CC}^{2} .1581,556\right)$

d. Că ACESTA amu iaste [care de el e scris] $\left(\mathrm{CC}^{2} .1581,590\right)$

Exemplele de sub $(7 \mathrm{a}, \mathrm{b})$ conțin un nume propriu focalizat, un numeral $(7 \mathrm{c})$, respectiv un DP complex $(7 \mathrm{~d})$ extras din poziție de subiect. Construcții de acest tip sînt posibile în româna actuală numai cu relativă cu antecedent.

(7) a. Minea proroc iaste [de-au prorocit de aceasta] $\left(\mathrm{CC}^{2} .1581,562\right)$

b. PAVEL iaste [carile mărturisește adevărata a Domnului făgadă] (...) (CD.1698, 164)

c. DoAO era [de ținea ruda omenească]: dulceața și scîrba. $\left(\mathrm{CC}^{2} .1581,520\right)$

d. că NUMAI SINGURĂ DREPTATEA iaste [de-i face cinstiț la norod]. (AD.1722-5, 86, 78 )

Se regăsesc în corpus și exemple în care constituentul focalizat este extras din poziție de obiect direct $(8 \mathrm{a}, \mathrm{b})$ sau obiect prepozițional (8c,d); și în aceste exemple, conectorul relativ poate fi diferit de $c e$ :

\footnotetext{
${ }^{2}$ Absența expletivului din construcția scindată este justificată sintactic, date fiind trăsăturile tipologice ale românei, de limbă pro-drop.
} 
(8) a. Și acum, ACEASTA iaste [care te rog, Doamne împărate], și [care cer de la tine]! (вв.1688, 644)

b. ACEasta iaste [ce dzice Pavel apostol să să socotească omul sîngur pre sine] (CazV.1643, $\left.43^{\mathrm{r}}\right)$

c. Aceasta iaste [care au zis Domnul] (вв.1688,76)

d. Deaci ACEA iaste [de ce grăim de stepena întăia a tatălui...] (Prav.1581, 167, 220v)

\subsection{Construcții pseudo-scindate inverse}

Cele mai numeroase în corpusul de limbă veche sînt exemplele în care focalizarea unui constituent se produce prin pseudo-scindare inversă (după schema din (4b): [XP FOCALIZAT + copulă + antecedent + relativă]). Sub aspectul realizării grupului aflat sub focus, remarcăm frecvența mare a pronumelor personale $(9 a-c)$, demonstrative $(9 d-f)$ și demonstrative profrază $(9 g)$, indefinite $(9 \mathrm{~h})$, dar și a numelor proprii (10), bine reprezentate în texte din toate perioadele.

(9) a. Etă, EU sîntu cela [ce căutați]! (Св.1559-60, 109)

b. Împărate Alexandre, EU sîmt astăzi cela [ce fugi de leul] $($ A.1620, 187)

c. EL iaste cela [ce ispitește inimile și rărunchii] (AD.1722-5, 92, 82 ${ }^{\mathrm{v}}$ )

d. ACESTA e cela [ce împărăția răsărita și apusul]. (FD.1592-604,483 ${ }^{\mathrm{r}}$ )

e. Au nu iaste ACESTA cela [ce ședea de cerea]? (CazV.1643, 168 ${ }^{\mathrm{r}}$ )

f. Cela ce are poruncile mele și le păzește pre iale, ACELA iaste cela [ce mă iubește] (AD.1722$\left.5,79,71^{\mathrm{v}}\right)$

g. Și ACEASTA iaste aceia [ce zice prorocul Ioil] (AD.1722-5, 219, 200v)

h. că ALTUL iaste cela [ce samănă], și ALTUL $\sqrt{ }$ cela [ce seaceră] $\left(\mathrm{CazV} .1643,160^{\mathrm{r}}\right)$

(10) a. SAVL era acesta [ce vrea uciderea lui] (св.1559-60, 81)

b. SAVEL era cela [ce vrea uciderii lui] (CP.1570, 81)

c. Că DumnezăU iaste Cel [ce zdrobeaște războaiele] (вв.1688, 632)

d. Duse-se omul și vestiia jidovilor că IIsus iaste Cela [ce l-au făcut pre el sănătos] (Bв.1688, 816)

e. IIsUs iaste cela [ce m-au făcut sănătos] (CazV.1643, 151 $\left.{ }^{\mathrm{v}}\right)$

f. Cunoașteți dară că Domnul iaste Cel [ce au turburat] $($ вв.1688, 371)

g. Alexandru vodă au fost acel [ce s-au bătut cu Pătru vodă Aron] (AU.1700, 53)

\subsection{Construcții pseudo-scindate hibride}

O variantă hibridă de construcție scindată regăsim în exemplele de sub (11). Tiparul amalgamează structura construcției scindate prototipice (avînd în locul expletivului un subiect lexicalizat) cu structura pseudoscindată inversă. Constituentul extras și adus sub focus este inclus aici într-o predicaţie de identificare, care face dificilă refacerea relației cu poziția de extracție [v. și ezitarea de acord din (11a) vs. (11b)]. Schema pe care o propunem pentru aceste construcții este [subiect lexicalizat + copulă + XP FOCALIZAT + antecedent + relativă]. Cu toate că tiparele prototipice sînt alterate, considerăm că putem vorbi și în aceste exemple de structuri scindate, emfaza construcției fiind evidentă.

(11) a. Eu sîntu Isus, cela [ce-l tu gonești] (Св.1559-60, 93)

b. Eu sînt Isus Nazarineanul, cela [ce tu mă gonești] (CP.1570, 93)

c. Acela iaste Moisi cela [ce zise fiilor lu Israil] (Св.1559-60, 75)

d. Acesta iaste Hristos, Isus cela [ce-1 spuiu eu voao] (св.1559-60, 181)

e. Acela iaste Isus Hristos [ce elu-l eu spuiu voao] (CP.1570, 181)

f. acela iaste IlıIE [cela [ce va să vie]] $\left(\mathrm{CC}^{2} .1581,585\right)$

g. aceasta iaste PÎINEA [carea au dat voao a vă hrăni] $($ PO.1582, 232) 
h. Acesta iaste omul [cel [ce spre oamini și despre Leage și spre locul acesta toți, tutuindenea învăță]] (...) (св.1559-60, 230)

i. Că acesta iaste OMUL ACELA [ce spre oameni și spre Leage și spre locul acesta toți, tutindirea învață] (...) (CP.1570, 230)

Exemplul (12) este interesant prin organizarea diferită a constituenților structurii (cu copula antepusă față de XP focalizat), determinată de prezența negației şi de natura semantică a constituentului focalizat (un cuantificator indefinit inclus într-un grup cu cap vid). În același timp, exemplul se detaşează de cele anterioare și pentru că nelexicalizarea centrului DP face dificilă încadrarea fără echivoc a construcției în tiparul pseudo-scindat prototpic (12a) sau pseudo-scindat (invers) cu antecedent (12a').

(12) a. Den aceastea toate, nu-s MULTE $\sqrt{ }$ [care n-au ieșit în limba rumînească den ceale cărți sîrbești și grecești]. (Po.1582, Prefață, $3^{\mathrm{r}}$ )

a.' Den aceastea toate, nu-s MULTe [CĂRȚi] [cele] [care n-au ieșit în limba rumânească den ceale cărți sîrbești și grecești]. (Po.1582, Prefaţă, $3^{\mathrm{r}}$ )

S-ar putea include în categoria structurilor hibride și construcții interogative precum (13), negative ca (14a,b), în care elementul focalizat este un cuantificator negativ nelexicalizat și construcții atipice cu relativă redusă (15a) sau eliptică (15b); toate au în comun emfaza, focalizarea unui constituent și includerea într-o structură care „rupe” organizarea canonică a enunțului.

(13) Mirară-se toți ceia ce auzia și grăiia: De nu ACESTA iaste cela [ce spărgea besearecile în Ierusalim ceia ce meniia numele acesta ...]? (CP.1570, 98)

(14) a. Nu iaste $\sqrt{ }$ [ca să rîdice sicriiul lui Dumnezău], fără numai leviții $($ B B.1688, 298)

b. Nu iaste $\sqrt{ }$ cel $[$ ce să știe calea ei], nici $\sqrt{ }$ cel $[$ ce să pomenească cărarea ei] $($ Bв.1688, 635)

(15) a. Fu Petru cercetîndu toți a deștenge cătră svinții ceia ce viia întru Lida (CP.1570, 100)

b. Era FIIUL LUI cela $\sqrt{ }$ mai marele la sat. $\left(\mathrm{CC}^{2} .1581,12\right)$

\section{Concluzii}

Analiza corpusului a arătat că, spre deosebire de româna modernă, româna veche prezintă o mai mare varietate de tipare, atît în privința organizării structurii, cît și în privinţa procedeelor de focalizare a constituentului. Absența din corpus a construcțiilor pseudo-scindate de bază (mult mai frecvente în româna modernă în comparație cu cele inverse) pare să confirme intuiția că tiparul de construcție pseudo-scindată din româna modernă se bazează pe un model francez sau italian și că este relativ recent. Pe de altă parte, varietatea sub toate aspectele a acestor construcții, inclusiv formulele hibride (a căror organizare poate fi pusă și pe seama unor modele străine) arată că tiparul de construcție scindată nu este accidental în limba veche, ci reprezenta o opțiune sintactică validă pentru strategiile de focalizare a unui constituent.

\section{Bibliografie}

\section{A. Corpus}

A.1620 = Alexandria, în Zgraon, Fl. (ed.), Cele mai vechi cărți populare în literatura română, vol. 11, Fundația Națională pentru Știință și Artă, București, 2006.

AD.1722-5 = Antim Ivireanul, Didahii, în Antim Ivireanul, Opere, ed. G. Ștrempel, Editura Minerva, București, 1972, p. 1238.

AU.1700 = Axinte Uricariul, Cronica paralelă a Țării Românești și a Moldovei, ediție critică și studiu introductiv de Gabriel Ștrempel, Editura Minerva, București, 1993.

вв.1688 = Biblia adecă Dumnezeiasca Scriptură a Vechiului și Noului Testament, tipărită întîia oară la 1688 în timpul lui Șerban Vodă Cantacuzino, Domnul Țării Românești, Editura Institutului Biblic, București, 1977.

CazV.1643 = Varlaam, Cazania, ed. J. Byck, Fundația Regală pentru Literatură și Artă, București, 1943, p. 1-506. 
Св.1559-60 = Codicele Bratul, ed. Al. Gafton, [online].

$\mathrm{CC}^{2} .1581$ = Coresi, Cartea cu învățătură, ed. S. Pușcariu \& Al. Procopovici, Atelierele Grafice Socec, București, 1914.

CD.1698 = Dimitrie Cantemir, Divanul, în D. Cantemir, Opere complete, I, Divanul, ed. V. Cîndea, Editura Academiei RSR, București, 1974, p. 103-405.

CP. 1570 = Coresi, Psaltirea slavo-română (1577) in comparație cu psaltirile coresiene din 1570 și din 1589, ed. S. Toma, Editura

Academiei RSR, București, 1976, p. 35-662.

FD.1592-604 = Floarea darurilor, în Roman Moraru, Al. (ed.) (1996). Cele mai vechi cărți populare în literatura română, 1,

Editura Minerva, București, p. 119-182.

PH.1500-1510 = Psaltirea Hurmuzaki, ed. I. Gheție \& M. Teodorescu, Editura Academiei Române, București, 2005.

Po.1582 = Palia de la Orăștie, ed. V. Pamfil, Editura Academiei RSR, București, 1968.

Prav.1581 = Pravila ritorului Lucaci, ed. I. Rizescu, Editura Academiei RSR, București, 1971, p. 161-183.

\section{B. Referințe}

Akmajian, A. (1970). On Deriving Cleft Sentences from Pseudo-Cleft Sentences, în „Linguistic Inquiry”, vol. 1, nr. 2, p. 149-168, [online].

Boškovic, Ž. (1997). Pseudoclefts, în „Studia Linguistica”, vol. 51, nr. 3, p. 235-277, Crossref.

Collins, P. (1991). Clefts and Pseudo-Cleft Constructions in English, Routledge, London \& New York.

Declerck, R. (1984). The pragmatics of it-clefts and WH-clefts, în „Lingua”, vol. 64, nr. 4, p. 251-289, Crossref.

Declerck, R. (1988). Studies in Copular Sentences, Clefts and Pseudo-clefts, Foris Publications, Holland/USA, Crossref.

Gheorghe, M. (2004). Propoziția relativă, Editura Paralela 45, Pitești.

Gundel, J.K. (1977). Where do cleft sentences come from?, în „Language”, vol. 53, nr. 3, p. 543-559, Crossref.

Halliday, M.A.K. (1985). An Introduction to Functional Grammar, Edward Arnold, London.

Hartmann, K. \& Tonjes V. (eds) (2013). Cleft Structures, John Benjamins Publishing Company, Amsterdam, Crossref.

Hedberg, N. (2013). Multiple focus and cleft sentences, în Hartmann \& Tonjes (2013), p. 227-250, Crossref.

Higgins, F. R. (1979). The Pseudo-cleft Construction in English, Garland Publishing, New York, Crossref.

Huddlestone, R., Pullum, G.K. et al. (2002). The Cambridge Grammar of the English Language, Cambridge University Press.

Iatridou, S. \& Varlokosta, S. (1998). Pseudoclefts crosslinguistically, în „Natural Language Semantics”, vol. 6, nr. 1, p. 3-28, Crossref.

Jespersen, O. (1937/1984). Analytic Syntax, The University of Chicago Press.

Lambrecht, K. (2001). A Framework for the Analysis of Cleft Constructions, în „Linguistics”, vol. 39, nr. 3, p. 463-516, Crossref. Pană Dindelegan, G. (ed.) (2013). The Grammar of Romanian, Oxford University Press.

Prince, E. F. (1978). A comparison of Wh-clefts and it-clefts in discourse, în „Language”, vol. 54, nr. 4, p. 883-906, Crossref.

Prince, E. F. (1981). Toward a taxonomy of given-new information, în Cole, P. (ed.), Radical Pragmatics, Academic Press, New York, p. 223-255.

Reeve, M. (2011). The syntactic structure of English clefts, în „Lingua”, vol. 121, nr. 2, p. 142-71, Crossref.

Reeve, M. (2012). Clefts and their Relatives, John Benjamins Publishing Company, Amsterdam, Crossref.

Șerbănescu, A. (1996). Construcții scindate, în „Limba Română”, vol. 35, nr. 1, p. 3-10. 